\title{
Partition Efficiency of Eccentric Coil for Countercurrent Chromatographic Separation of Proteins Using Small-scale Cross-axis Coil Planet Centrifuge with Circular and Elliptic Cylindrical Columns
}

\author{
Kazufusa ShinomiYa, ${ }^{* \dagger}$ Koji ToKura, $* *$ Tomomi Hashimoto,* Ruina Watanabe,* Tomoya Takeda,* \\ Kazumasa ZAIMA, ${ }^{*}$ and Yoichiro ITO ${ }^{* * *}$ \\ *School of Pharmacy, Nihon University, 7-7-1 Narashinodai, Funabashi, Chiba 274-8555, Japan \\ **College of Science and Technology, Nihon University, 7-24-1 Narashinodai, Funabashi, Chiba 274-8501, Japan \\ ***Laboratory of Bioseparation Technology, Biochemistry and Biophysics Center, Division of Intramural \\ Research, National Heart, Lung, and Blood Institute, National Institutes of Health, 10 Center Drive, \\ MSC 1762, Building 10, Room 5D18, Bethesda, MD 20892-1762, USA
}

\begin{abstract}
The partition efficiency of the double-spaced coil for eccentric and toroidal coils on countercurrent chromatographic separation of proteins was evaluated using the small-scale cross-axis coil planet centrifuge (CPC) equipped with circular and elliptic cylindrical columns. Standard cytochrome $c$, myoglobin and lysozyme samples were used for separation with the $12.5 \%(\mathrm{w} / \mathrm{w})$ polyethylene glycol 1000 and $12.5 \%(\mathrm{w} / \mathrm{w})$ dibasic potassium phosphate system. In the circular column, the double-spaced eccentric coil yielded better peak resolution than the double-spaced toroidal coil, and the double-spaced eccentric coil yielded better peak resolution than the single-spaced eccentric coil. In the elliptic column, the doublespaced eccentric coil also produced better peak resolution than the double-spaced toroidal coil, but the single-spaced eccentric coil yielded better peak resolution than the double-spaced eccentric coil. The overall results indicated that the double-spaced eccentric coil for the circular column and the single-spaced eccentric coil for the elliptic column yielded better protein separation using the small-scale cross-axis CPC with aqueous two-phase solvent systems.
\end{abstract}

Keywords Countercurrent chromatography, cross-axis coil planet centrifuge, partition efficiency, protein separation, aqueous two-phase solvent system, coil pitch

(Received August 7, 2020; Accepted October 9, 2020; Advance Publication Released Online by J-STAGE October 23, 2020)

\section{Introduction}

Countercurrent chromatography (CCC) is a unique separation technique based on the partition of solutes between two immiscible solvent phases present in the separation column. ${ }^{1}$ The elimination of the solid support matrix provides the advantage especially for the separation and purification of natural products ${ }^{2}$ over common column chromatography. ${ }^{3}$ In order to achieve higher partition efficiency, including the peak resolution and the stationary phase retention, many hydrostatic and hydrodynamic types of CCC instruments have been developed by a number of researchers. ${ }^{4}$ In the hydrodynamic CCC machines, high-speed countercurrent chromatography (HSCCC), mainly including the type-J coil planet centrifuge (CPC) and the cross-axis CPC, has been most effective for the separation of various chemical compounds. ${ }^{5}$ These two HSCCC instruments have remarkable rotation mechanisms in that in the type-J CPC the coiled column rotates about its own planet axis

† To whom correspondence should be addressed.

E-mail: shinomiya.kazufusa@nihon-u.ac.jp and revolves around the central sun axis in the same direction, while in the cross-axis CPC the coiled column rotates vertically about its own planet axis while revolving around the central sun axis in a horizontal plane. ${ }^{6,7}$ This dual synchronous column rotation of the cross-axis CPC brings about effective separation of hydrophilic macromolecules such as proteins with aqueous two-phase solvent systems, ${ }^{8,9}$ which are difficult to retain the stationary phase in the type-J CPC with the multilayer coiled column. ${ }^{19}$ In our previous studies, the small-scale cross-axis CPC has been designed and fabricated in the machinery department of our university and applied to CCC separation of proteins with aqueous two-phase solvent systems. ${ }^{10}$ The crossaxis CPC provides a simple and effective separation process for proteins at high purity from the biological matrix without denaturation and loss of bioactivity by the use of aqueous twophase solvent systems even having low interfacial tension. This apparatus has been improved in terms of the column positions, ${ }^{6-9,11-13}$ column configuration, ${ }^{14,15}$ revolution speed, ${ }^{16}$ elution modes, ${ }^{17}$ coil pitch $^{18}$ and so on.

In the HSCCC instruments, the circular cylindrical column holder has been generally used to achieve stable column rotation. In order to achieve higher partition efficiency, the mixing of two 
A. Circular cylindrical column holder

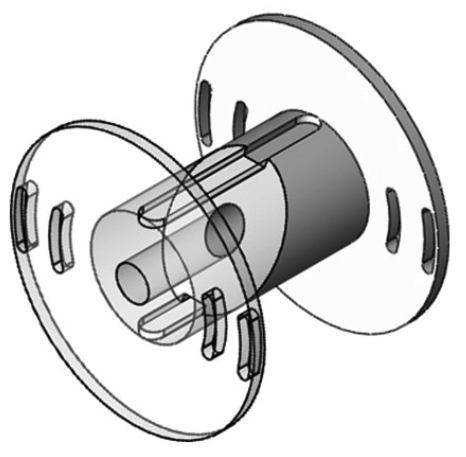

Diameter of the holder hub: $3 \mathrm{~cm}$

Diameter of the flange: $7 \mathrm{~cm}$

Distance between the flanges: $5 \mathrm{~cm}$
B. Elliptic cylindrical column holder

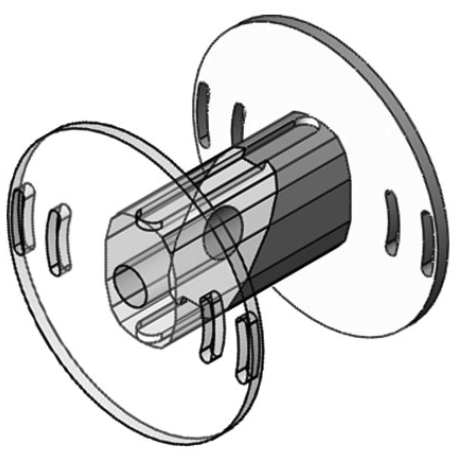

Major axis of the holder hub: $3 \mathrm{~cm}$ Minor axis of the holder hub: $2 \mathrm{~cm}$ Diameter of the flange: $7 \mathrm{~cm}$

Distance between the flanges: $5 \mathrm{~cm}$

Fig. 1 Schematic drawing of the circular (A) and the elliptic (B) cylindrical column holders for the small-scale cross-axis CPC.

phases in the rotating column should be increased. In the present study, the elliptic cylindrical column holder was newly designed and applied to protein separation using the small-scale cross-axis CPC with an aqueous two-phase solvent system, and then the partition efficiency including the peak resolution and the stationary phase retention was compared between these two cylindrical columns. Furthermore, two different types of coils, the eccentric and the toroidal coils, ${ }^{14,19,20}$ at both single-spaced and double-spaced coil pitches were used for the evaluation of the partition efficiency by mounting on the circular and the elliptic column holders, respectively, where the double-spaced coil was newly introduced in the present study to improve the partition efficiency.

\section{Experimental}

Apparatus and column holders

The small-scale cross-axis CPC introduced in the present study was constructed at the Machining Technology Center of the College of Science and Technology, Nihon University (Chiba, Japan). The details of the design and rotation mechanism of this apparatus were described in our previous publications. ${ }^{10,21}$

Two different types of column holders, the circular and the elliptic cylindrical column holders, were used in the present study as illustrated in Fig. 1. The dimensions of the column holders are described in this figure.

Preparation of the double-spaced coil unit for the eccentric and the toroidal coils

Figure 2A illustrates the fabrication procedure of the double spaced left-handed coil unit. This coil unit was made by winding a $1.0 \mathrm{~mm}$ i.d. and $2.0 \mathrm{~mm}$ o.d. PTFE (polytetrafluoroethylene) tubing (Flon Industry, Tokyo, Japan) onto a $6.0 \mathrm{~mm}$ o.d. nylon pipe, leaving a space of the outer diameter of the tubing between each coil to form the first left-handed coil. When the coil reached the end of the pipe, the tube was straightly returned to the top through the inside of the pipe. Then, the tube was wound again to fill the space between the first coils to form the second left-handed coil. In the present study, four kinds of coils, the double-spaced and the single-spaced eccentric
A.

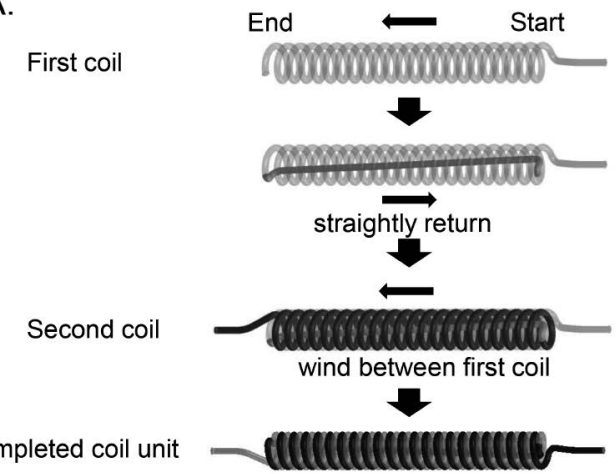

B.

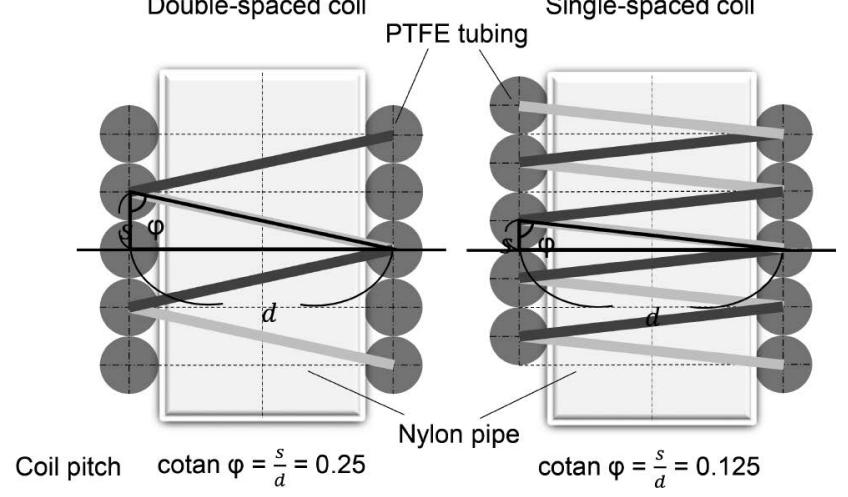

Fig. 2 Fabrication of the double-spaced coil (A) and the difference of the lead angle between the double-spaced and the single-spaced coils (B).

coils, and the double-spaced and the single-spaced toroidal coils, were mounted on the circular and the elliptic column holders, respectively.

The coil pitch is conventionally expressed by $\operatorname{cotan} \varphi$ as illustrated in Fig. 2B. This value of the double-spaced coil was twice as large as that of the single-spaced coil. 


\section{A. Double-Spaced Eccentric Coiled Circular Column}

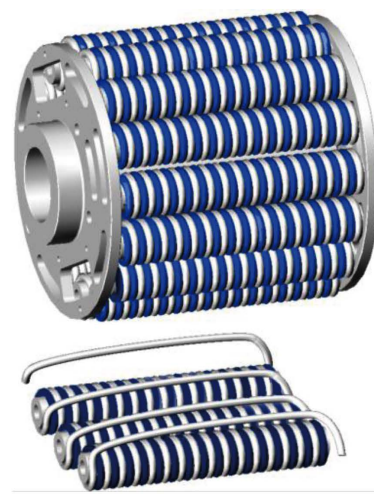

\section{B. Double-Spaced Toroidal Coiled Circular Column}
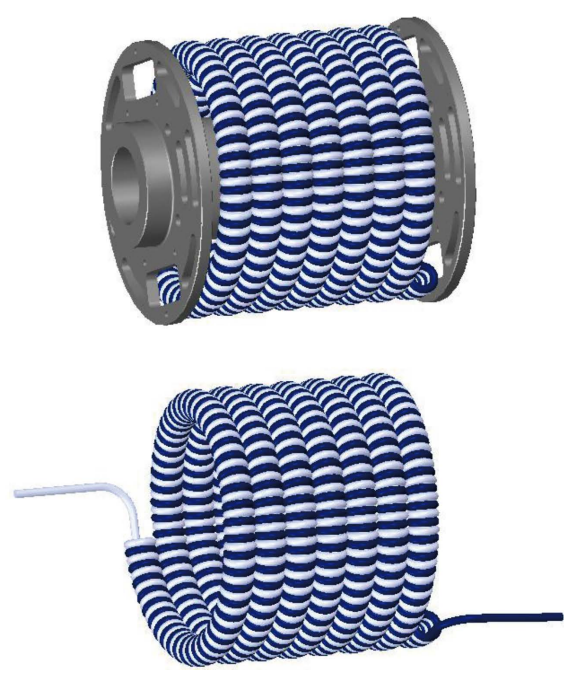

Fig. 3 Schematic drawing of the double-spaced eccentric and toroidal coiled circular columns for the small-scale cross-axis CPC.

\section{Preparation of the coiled columns}

As illustrated in Fig. 3A, the eccentric coiled column was manufactured by mounting the eccentric coil units symmetrically around the holder hub in such a way that the axis of each coil unit (double-spaced eccentric coil: $5 \mathrm{~cm}$ long and 9 turns $\times 2$, single-spaced eccentric coil: $5 \mathrm{~cm}$ long and 19 turns) was parallel to the holder axis (11 units for the first layer and 18 units for the second layer in both double-spaced and singlespaced eccentric coil assembly). In the counterclockwise $(\mathrm{CCW})$ revolution of the rotary frame, forward rotating columns were arranged in the order of the left-handed eccentric coil units into the left-handed direction from the view of the central shaft and neighboring backward rotating columns were arranged in the order of the right-handed eccentric coil units into the righthanded direction. Four eccentric coiled columns were mounted symmetrically on the rotary frame and connected by a single flow tube distribution line to achieve the rotation stability of the centrifuge instrument. The total column content was $56.0 \mathrm{~mL}$ for the double-spaced eccentric coiled column and $66.0 \mathrm{~mL}$ for the single-spaced eccentric coiled column.

As illustrated in Fig. 3B, the toroidal coiled column was manufactured by mounting the toroidal coil units to form double layers. After the first layer of the toroidal coil unit (the doublespaced coil: $60 \mathrm{~cm}$ long and 128 turns $\times 2$, the single-spaced coil: $60 \mathrm{~cm}$ long and 256 turns) was wound around the column holder to form a left-handed or a right-handed coil, the PTFE tubing of the first layer that had reached the distal side was straightly returned to the proximal side. Then, the tubing was connected to the second layer of the toroidal coil unit (the double-spaced coil: $90 \mathrm{~cm}$ long and 188 turns $\times 2$, the singlespaced coil: $90 \mathrm{~cm}$ long and 399 turns). In the $\mathrm{CCW}$ revolution of the rotary frame, forward rotating columns were arranged in the order of the left-handed toroidal coil units into the lefthanded direction from the view of the central shaft and neighboring backward rotating columns were arranged in the order of the right-handed toroidal coil units into the righthanded direction. Four toroidal coiled columns were mounted symmetrically on the rotary frame and connected by a single flow tube distribution line to obtain a total content of $70.0 \mathrm{~mL}$ for the double-spaced toroidal coiled column and $64.0 \mathrm{~mL}$ for the single-spaced toroidal coiled column.

\section{Reagents}

Polyethylene glycol (PEG) 1000 (MW 1000), cytochrome $c$ (horse heart) (MW 12384), myoglobin (horse skeletal muscle) (MW 17800), and lysozyme (chicken egg) (MW 13680) were purchased from Sigma (St. Louis, MO, USA). Dibasic potassium phosphate was obtained from FUJI FILM Wako Pure Chemical Co. (Osaka, Japan). All other reagents were of reagent grade.

Preparation of an aqueous two-phase solvent system and sample solutions

An aqueous two-phase solvent system composed of $12.5 \%$ (w/w) PEG 1000 and $12.5 \%$ (w/w) dibasic potassium phosphate was prepared by dissolving $125 \mathrm{~g}$ of PEG 1000 and $125 \mathrm{~g}$ of dibasic potassium phosphate (anhydrous) in $750 \mathrm{~g}$ of distilled water. The PEG-rich solution forms the upper phase and the phosphate salt-rich solution, the lower phase.

The sample solution was prepared by dissolving the standard protein mixture with equal volumes of each phase of the aqueous two-phase solvent system used for CCC separation.

\section{CCC separation}

Before each separation, the PEG-rich upper stationary phase was initially filled in the coiled column and the sample solution was injected through the flow tube leading into the head of the CCC column with a syringe. Then, the phosphate salt-rich lower mobile phase was pumped into the column at a suitable flow rate using a reciprocating pump (Model LC-10ADVP, Shimadzu Corporation, Kyoto, Japan), while the column was rotated at $900 \mathrm{rpm}$ of revolution speed in the $\mathrm{CCW}$ direction. The effluent from the column outlet was collected into test tubes using a fraction collector (Model CHF 100AA, Advantec, Tokyo, Japan).

\section{Analysis of CCC fractions}

Each collected fraction of proteins was diluted with an aliquot 
of water and the absorbance was measured at $280 \mathrm{~nm}$ with the spectrophotometer (Model UV-1800, Shimadzu).

\section{Evaluation of partition efficiency}

The partition efficiency in each separation was evaluated by the peak resolution (Rs) computed from the chromatogram according to the conventional formula and the stationary phase retention directly measured after each separation. ${ }^{3}$

\section{Results and Discussion}

The usefulness of the eccentric coil and the toroidal coil has already been demonstrated by the CCC separation using the type-J CPC for proteins ${ }^{19}$ and the coil satellite centrifuge for sugar derivatives, ${ }^{20}$ which were difficult to separate with the multilayer coiled column. In the present study, the partition efficiencies of the single-spaced and the double-spaced eccentric and toroidal coils were evaluated by the CCC separation of proteins using the small-scale cross-axis CPC with the circular and the elliptic columns.

\section{CCC separation of proteins with the circular column}

Protein separation was performed using a set of standard protein samples including cytochrome $c$ (Cyt $c$ ), myoglobin (Myo) and lysozyme (Lys) with the lower mobile phase of an aqueous two-phase solvent system composed of $12.5 \%$ (w/w)
PEG 1000 and $12.5 \%(\mathrm{w} / \mathrm{w})$ dibasic potassium phosphate. In order to determine the suitable flow rate for separation, the peak resolution and the stationary phase retention were measured from the CCC separation of proteins obtained using the smallscale cross-axis CPC with the double-spaced eccentric coiled circular column at various flow rates. As summarized in Table 1, a lower flow rate produced increased peak resolution and stationary phase retention. From these results, two different flow rates, 0.5 and $0.7 \mathrm{~mL} / \mathrm{min}$, were selected for use in protein

Table 1 Effect of flow rate of the lower mobile phase on the peak resolution and the stationary phase retention obtained from protein separation using the small-scale cross-axis CPC with the double-spaced eccentric coiled circular column

\begin{tabular}{cccc}
\hline \multirow{2}{*}{$\begin{array}{c}\text { Flow rate/ } \\
\text { mL min }^{-1}\end{array}$} & \multicolumn{2}{c}{ Peak resolution (Rs) } & $\begin{array}{c}\text { Stationary phase } \\
\text { retention, } \%\end{array}$ \\
\cline { 2 - 3 } Cyt $c /$ Myo & Myo/Lys & 33.6 \\
0.5 & 1.24 & 1.49 & 30.4 \\
0.6 & 1.10 & 1.25 & 26.8 \\
0.9 & 1.00 & 1.30 & 28.6 \\
1.1 & 0.90 & 1.01 & 23.2 \\
1.3 & 0.97 & 1.05 & 20.5 \\
\hline
\end{tabular}

Abbreviations: Cyt $c$ =cytochrome $c ;$ Myo=myoglobin; Lys = lysozyme.
Double-spaced eccentric coil

A. Flow rate $0.5 \mathrm{~mL} \mathrm{~min}^{-1}$

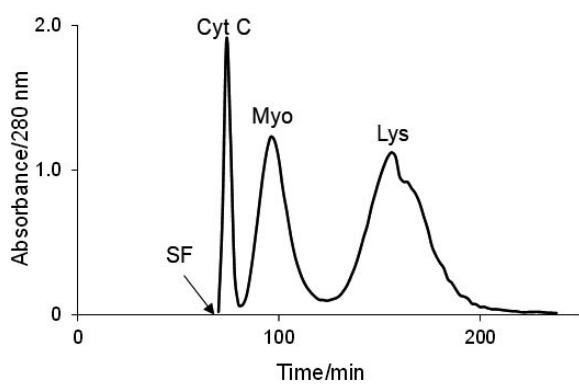

B. Flow rate $0.7 \mathrm{~mL} \mathrm{~min}^{-1}$

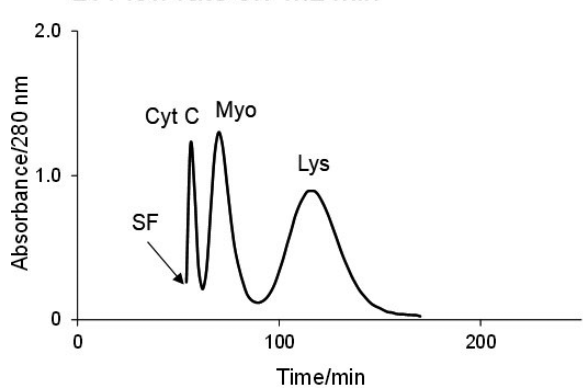

\section{Double-spaced toroidal coil}
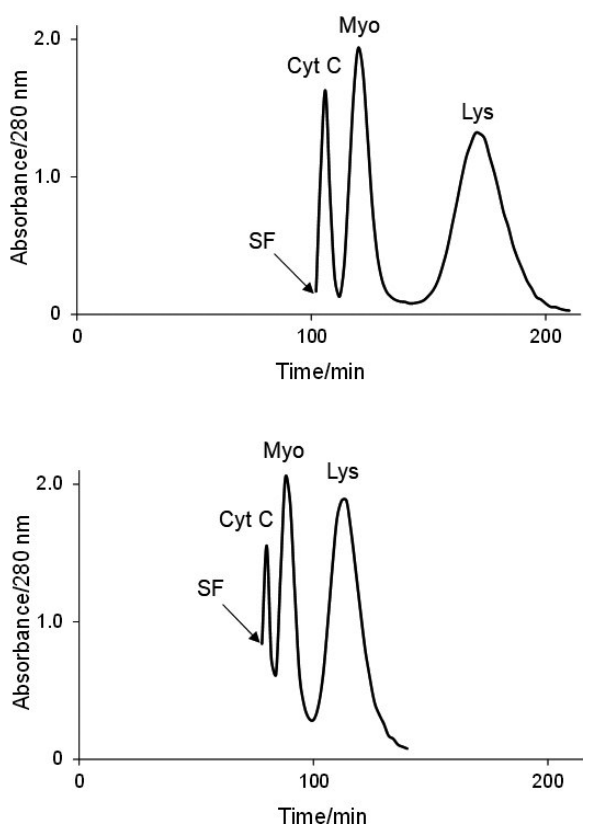

Fig. 4 CCC chromatograms of proteins obtained using the small-scale cross-axis CPC with the double-spaced coil for the circular column. Experimental conditions: apparatus: small-scale cross-axis CPC; column: double-spaced eccentric coil ( $1.0 \mathrm{~mm}$ i.d., $2.0 \mathrm{~mm}$ o.d. PTFE tubing, $6.0 \mathrm{~mm}$ o.d., $5 \mathrm{~cm}$ long nylon pipe, 9 turns $\times 2$ for each coil unit, 11 units for the first layer and 18 units for the second layer, four columns, total capacity: $56.0 \mathrm{~mL}$ ) and double-spaced toroidal coil (1.0 mm i.d., $2.0 \mathrm{~mm}$ o.d. PTFE tubing, $6.0 \mathrm{~mm}$ o.d. nylon pipe, $60 \mathrm{~cm}$ long and 128 turns $\times 2$ for the first layer, $90 \mathrm{~cm}$ long and 188 turns $\times 2$ for the second layer, four columns, total capacity: $70.0 \mathrm{~mL})$; solvent system: $12.5 \%(\mathrm{w} / \mathrm{w})$ PEG 1000 - 12.5\% (w/w) dibasic potassium phosphate; mobile phase: lower phase; sample: cytochrome $c(2.5 \mathrm{mg})$, myoglobin $\left(8 \mathrm{mg}\right.$ ) and lysozyme (10 mg); flow rate: (A) $0.5 \mathrm{~mL} \mathrm{~min}{ }^{-1}$ and (B) $0.7 \mathrm{~mL} \mathrm{~min}^{-1}$; fractionate: $2 \mathrm{~min} /$ tube; rotation speed: $900 \mathrm{rpm}$; revolution direction: counterclockwise; detection: $280 \mathrm{~nm} . \mathrm{SF}=$ solvent front. 
Single-spaced eccentric coil

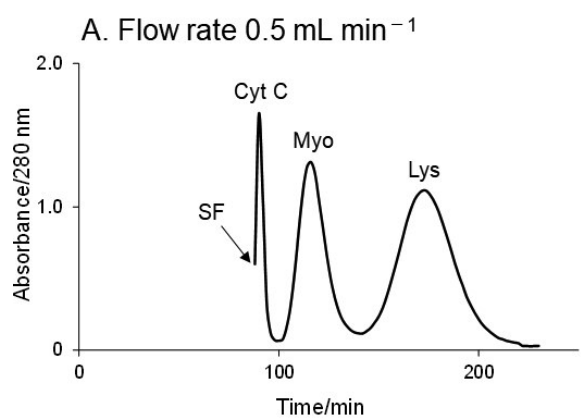

B. Flow rate $0.7 \mathrm{~mL} \mathrm{~min}^{-1}$

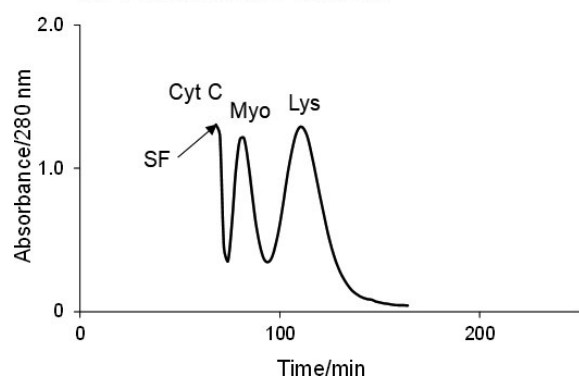

Single-spaced toroidal coil
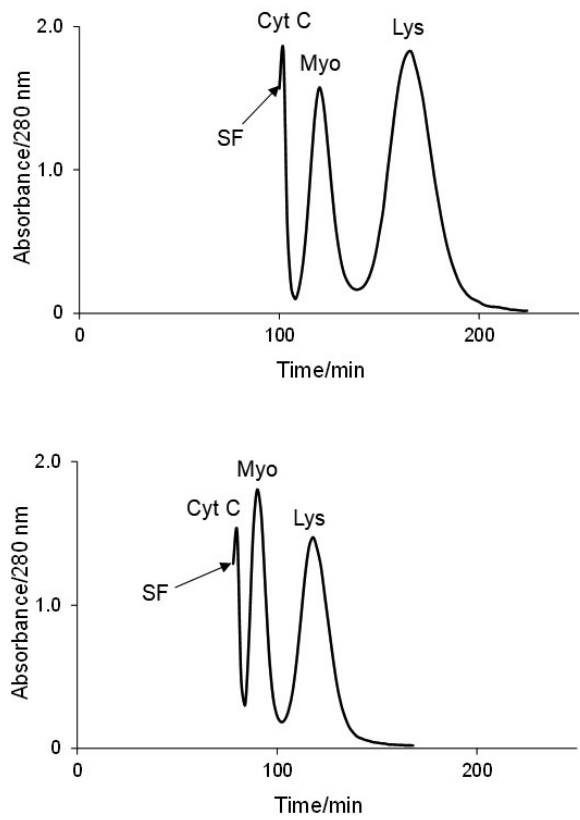

Fig. 5 CCC chromatograms of proteins obtained using the small-scale cross-axis CPC with the single-spaced coil for the circular column. Experimental conditions: column: single-spaced eccentric coil ( $1.0 \mathrm{~mm}$ i.d., $2.0 \mathrm{~mm}$ o.d. PTFE tubing, $6.0 \mathrm{~mm}$ o.d., $5 \mathrm{~cm}$ long nylon pipe, 19 turns for each coil unit, 11 units for the first layer and 18 units for the second layer, four columns, total capacity: $66.0 \mathrm{~mL}$ ) and single-spaced toroidal coil $(1.0 \mathrm{~mm}$ i.d., $2.0 \mathrm{~mm}$ o.d. PTFE tubing, $6.0 \mathrm{~mm}$ o.d. nylon pipe, $60 \mathrm{~cm}$ long and 256 turns for the first layer, $90 \mathrm{~cm}$ long and 399 turns for the second layer, four columns, total capacity: $64.0 \mathrm{~mL}$ ). Other experimental conditions were the same as those described in the Fig. 4 caption.

separation with the double-spaced and the single-spaced eccentric and toroidal coils for the circular and the elliptic columns.

Figure 4 illustrates the CCC separation of proteins obtained using the small-scale cross-axis CPC with the double-spaced eccentric and toroidal coiled circular columns. The results showed that at both low and high flow rates, better peak resolution of proteins was obtained by the double-spaced eccentric coil than by the double-spaced toroidal coil.

Figure 5 illustrates the CCC separation of proteins obtained using the small-scale cross-axis CPC with the single-spaced eccentric and toroidal coiled circular columns. As with the double-spaced coil, better peak resolution was obtained by the single-spaced eccentric coil than by the single-spaced toroidal coil.

Table 2 summarizes the analytical values computed from the CCC chromatograms obtained using the double-spaced and the single-spaced eccentric and toroidal coiled circular columns. Higher stationary phase retention was yielded by the doublespaced eccentric coil than by the single-spaced eccentric coil. At both low and high flow rates, better peak resolution was obtained by the double-spaced eccentric coil than by the singlespaced eccentric coil. The best separation was obtained by the double-spaced eccentric coil for the circular column at the peak resolution $\mathrm{Rs}_{1}(\mathrm{Cyt} c / \mathrm{Myo})=1.24$ and $\mathrm{Rs}_{2}(\mathrm{Myo} / \mathrm{Lys})=1.49$ with the stationary phase retention at $33.6 \%$.

\section{CCC separation of proteins with the elliptic column}

Figure 6 illustrates the CCC separation of proteins obtained using the small-scale cross-axis CPC with the double-spaced
Table 2 Analytical values of the peak resolution and the stationary phase retention obtained from protein separation using the small-scale cross-axis CPC with the double-spaced and the single-spaced eccentric and toroidal coiled circular columns

\begin{tabular}{ccccc}
\hline \multirow{2}{*}{$\begin{array}{c}\text { Circular } \\
\text { column }\end{array}$} & $\begin{array}{c}\text { Flow rate/ } \\
\mathrm{mL} \mathrm{min}^{-1}\end{array}$ & \multicolumn{2}{c}{ Peak resolution (Rs) } & $\begin{array}{c}\text { Stationary } \\
\text { phase }\end{array}$ \\
\cline { 3 - 4 } Double-spaced & & & & \\
eccentric coil & 0.5 & 1.24 & 1.49 & 33.6 \\
& 0.7 & 1.00 & 1.30 & 26.8 \\
retention, \%
\end{tabular}

eccentric and toroidal coiled elliptic columns. At both low and high flow rates, better peak resolution was obtained by the double-spaced eccentric coil than by the double-spaced toroidal coil where this tendency was the same as that in the circular column.

Figure 7 illustrates the CCC separation of proteins using the small-scale cross-axis CPC with the single-spaced eccentric and toroidal coiled elliptic columns. As with the double-spaced coil, better peak resolution was obtained by the single-spaced eccentric coil than by the single-spaced toroidal coil. 
Double-spaced eccentric coil

A. Flow rate $0.5 \mathrm{~mL} \mathrm{~min}^{-1}$

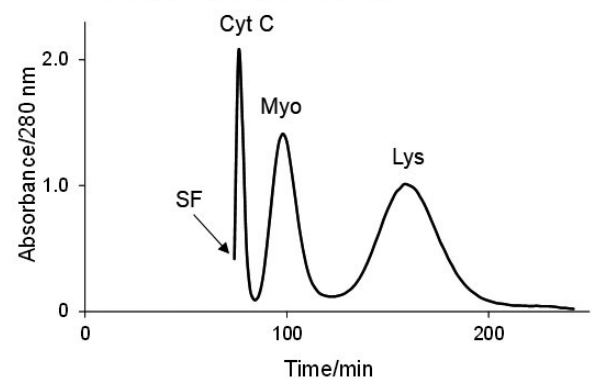

B. Flow rate $0.7 \mathrm{~mL} \mathrm{~min}^{-1}$

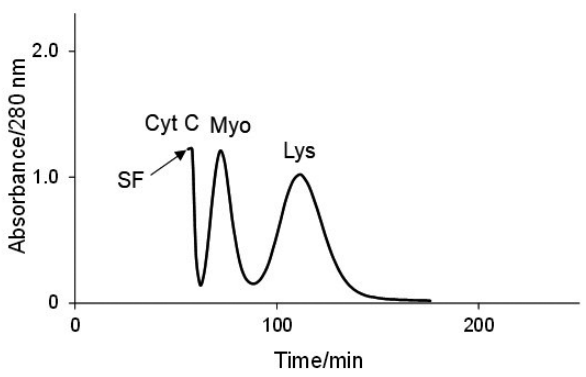

Double-spaced toroidal coil
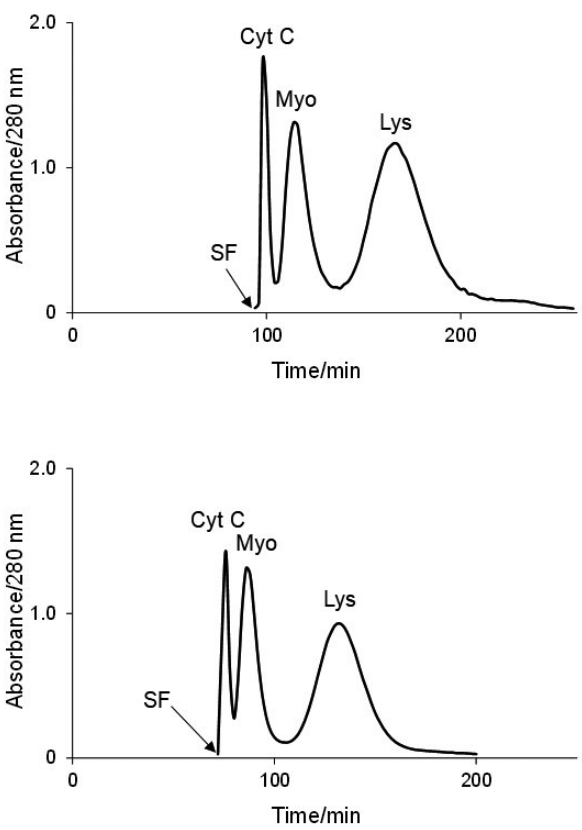

Fig. 6 CCC chromatograms of proteins obtained using the small-scale cross-axis CPC with the double-spaced coil for the elliptic column. Experimental conditions were the same as those described in the Fig. 4 caption.

Single-spaced eccentric coil

A. Flow rate $0.5 \mathrm{~mL} \mathrm{\textrm {min } ^ { - 1 }}$

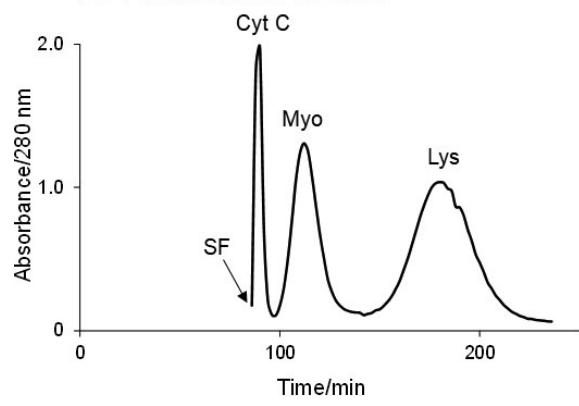

B. Flow rate $0.7 \mathrm{~mL} \mathrm{~min}^{-1}$

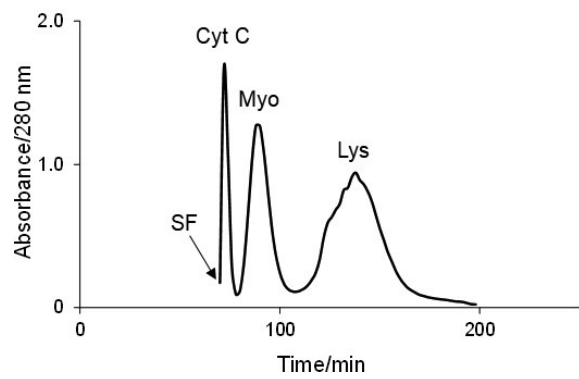

Single-spaced toroidal coil
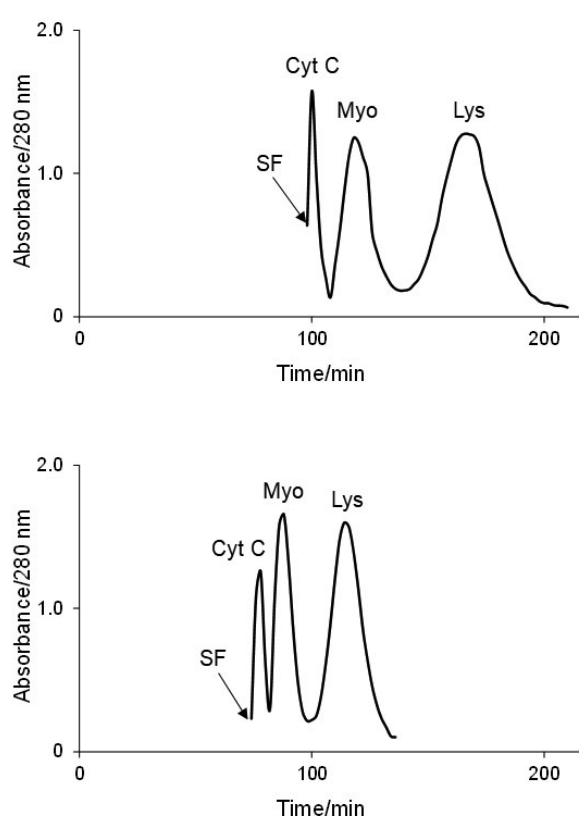

Fig. 7 CCC chromatograms of proteins obtained using the small-scale cross-axis CPC with the single-spaced coil for the elliptic column. Experimental conditions were the same as those described in the Fig. 5 caption.

Table 3 summarizes the analytical values computed from the $\mathrm{CCC}$ chromatograms obtained using the double-spaced and the single-spaced eccentric and toroidal coiled elliptic columns. Higher stationary phase retention was obtained by the double- spaced eccentric coil than by the single-spaced eccentric coil, which was the same as in the circular column. At a low flow rate, almost similar peak resolution was obtained between the double-spaced and the single-spaced eccentric coils, while at a 
Table 3 Analytical values of the peak resolution and the stationary phase retention obtained from protein separation using the small-scale cross-axis CPC with the double-spaced and the single-spaced eccentric and toroidal coiled elliptic columns

\begin{tabular}{ccccc}
\hline \multirow{2}{*}{$\begin{array}{c}\text { Elliptic } \\
\text { column }\end{array}$} & $\begin{array}{c}\text { Flow rate/ } \\
\mathrm{mL} \mathrm{min}^{-1}\end{array}$ & \multicolumn{2}{c}{ Peak resolution (Rs) } & $\begin{array}{c}\text { Stationary } \\
\text { phase }\end{array}$ \\
\cline { 3 - 4 } Double-spaced & & & & \\
eccentric coil & 0.5 & 1.25 & 1.40 & 32.1 \\
& 0.7 & 0.90 & 1.17 & 28.1 \\
retention, \%
\end{tabular}

high flow rate, increased peak resolution was obtained by the single-spaced eccentric coil than by the double-spaced eccentric coil. From this result, we concluded that better partition efficiency was obtained by the single-spaced eccentric coil than by the double-spaced eccentric coil. The best separation was obtained by the single-spaced eccentric coil for the elliptic column at the peak resolution $\mathrm{Rs}_{1}(\mathrm{Cyt} c / \mathrm{Myo})=1.23$ and $\mathrm{Rs}_{2}$ $(\mathrm{Myo} / \mathrm{Lys})=1.62$ with the stationary phase retention at $22.7 \%$.

This result was almost similar to that obtained using the circular column with the double-spaced eccentric coil, which was more improved than the result obtained by the common single-spaced eccentric coil for the circular column at the peak resolution $\mathrm{Rs}_{1}(\mathrm{Cyt} c / \mathrm{Myo})=1.20$ and $\mathrm{Rs}_{2}(\mathrm{Myo} / \mathrm{Lys})=1.31$ with the stationary phase retention at $28.8 \%$, as summarized in Table 2. In both the circular column and the elliptic column, better partition efficiency was obtained by the eccentric coil than by the toroidal coil. This may be caused by the difference of coil configuration between these coils where the difference of physical forces produced by the planetary motion results in the difference of the partition behavior of proteins in the rotating coil even though the column content, the revolution speed and the flow rate of the mobile phase were almost similar in these coils.

\section{Conclusions}

The overall results indicate that the double-spaced eccentric coil for the circular column and the single-spaced eccentric coil for the elliptic column are suitable for CCC separation of proteins using the small-scale cross-axis CPC with aqueous two-phase solvent systems. These valuable results will provide effective column configuration details to obtain higher partition efficiency in protein separation when using the HSCCC instruments with the circular or the elliptic cylindrical columns.

\section{Acknowledgements}

This work was in part supported by the "Private University Research Branding Project" from the Ministry of Education, Culture, Sports, Science and Technology.

\section{References}

1. N. B. Mandava and Y. Ito, "Countercurrent Chromatography: Theory and Practice", 1988, Marcel Dekker, New York.

2. W. D. Conway, "Countercurrent Chromatography: Apparatus, Theory \& Applications", 1990, VCH, Weinheim.

3. Y. Uto, K. Sasaki, M. Takahashi, K. Morimoto, and K. Inoue, Anal. Sci., 2019, 35, 789.

4. S. Kitagawa, Anal. Sci., 2019, 35, 949.

5. Y. Ito and W. D. Conway, "High-Speed Countercurrent Chromatography”, 1996, Wiley-Interscience, Amsterdam.

6. Y. Ito, Sep. Sci. Technol., 1987, 22, 1971.

7. Y. Ito, Sep. Sci. Technol., 1987, 22, 1989.

8. K. Shinomiya, J.-M. Menet, H. M. Fales, and Y. Ito, J. Chromatogr., 1993, 644, 215.

9. K. Shinomiya, M. Muto, Y. Kabasawa, H. M. Fales, and Y. Ito, J. Liq. Chromatogr. Relat. Technol., 1996, 19, 415.

10. K. Shinomiya, K. Yanagidaira, and Y. Ito, J. Chromatogr. A, 2006, 1104, 245.

11. Y. Ito, H. Oka, and J. Slemp, J. Chromatogr., 1989, 463, 305.

12. Y. Ito, E. Kitazume, M. Bhatnagar, and F. Trimble, J. Chromatogr., 1991, 538, 59.

13. Y. Shibusawa and Y. Ito, J. Liq. Chromatogr., 1992, 15, 2787.

14. K. Shinomiya, Y. Kabasawa, and Y. Ito, J. Liq. Chromatogr. Relat. Technol., 1998, 21, 111.

15. K. Shinomiya, Y. Kabasawa, and Y. Ito, J. Liq. Chromatogr. Relat. Technol., 2002, 25, 2665.

16. K. Shinomiya, Y. Kabasawa, and Y. Ito, J. Liq. Chromatogr. Relat. Technol., 1998, 21, 1727.

17. K. Shinomiya, Y. Kabasawa, and Y. Ito, Prep. Biochem. \& Biotechnol., 1999, 29, 139.

18. K. Shinomiya, H. Kobayashi, N. Inokuchi, K. Nakagomi, and Y. Ito, J. Liq. Chromatogr. Relat. Technol., 2011, 34, 182.

19. K. Shinomiya, K. Yoshida, K. Tokura, E. Tsukidate, K. Yanagidaira, and Y. Ito, Anal. Sci., 2015, 31, 211.

20. K. Shinomiya, K. Zaima, M. Yasue, R. Honda, Y. Sakuma, N. Harikai, K. Tokura, and Y. Ito, J. Chromatogr. A, 2019, 1596, 134.

21. K. Shinomiya, H. Kobayashi, N. Inokuchi, K. Kobayashi, H. Oshima, S. Kitanaka, K. Yanagidaira, H. Sasaki, M. Muto, M. Okano, and Y. Ito, J. Chromatogr. A, 2007, 1151, 91. 